\title{
Flying not flapping: a strategic framework for e-learning and pedagogical innovation in higher education institutions
}

\author{
Gilly Salmon* \\ University of Leicester, UK
}

E-learning is in a rather extraordinary position. It was born as a 'tool' and now finds itself in the guise of a somewhat wobbly arrow of change. In practice, changing the way thousands of teachers teach, learners learn, innovation is promoted and sustainable change in traditional institutions is achieved across hundreds of different disciplines is a demanding endeavour that will not be achieved by learning technologies alone. It involves art, craft and science as well as technology. This paper attempts to show how it might be possible to capture and model complex strategic processes that will help move the potential of e-learning in universities to a new stage of development. It offers the example of a four-quadrant model created as a framework for an e-learning strategy.

\section{Introduction}

Like most people, I am amused by human's early attempts to fly and especially at the focus on frantically flapping feathered wings, inspired by the observation of birds. The breakthrough to powered flight and subsequently flying for all came when the inventors rethought the conceptual approach and developed aircraft based upon fixed wings in a steady airflow.

The introduction of information and communications technologies (ICT) into the world of learning and teaching in universities is now in transition from 'flapping' to mass take off thanks to appropriate conceptual underpinnings. It too has passed through two stages. At first, learning technologies were seen as a new way of doing something familiar. This first stage is what might be thought of as the electronic classroom. The physical environment in which teaching and learning occurs is replaced to

\footnotetext{
*Professor of E-learning \& Learning Technologies, Beyond Distance Research Alliance, University of Leicester, University Road, Leicester LE1 7RH, UK. Email: Gilly.salmon@1e.ac.uk
} 
some extent, but the processes of teaching, the essential pedagogical approach and the underlying assumptions about learning and knowledge sharing remain largely unchanged. In these circumstances, there is a risk that the widespread adoption of easy-to-use learning technologies such as Virtual Learning Environments (VLEs) may be mistaken for educational innovation (Westera, 2004). In the second phase however, learning technologies are used in new ways, to advance beyond what was possible in the classroom or to combine traditional approaches with e-learning in effective and worthwhile modes to meet new objectives and purposes of teaching and learning.

Many projects, authors and managers in higher education institutions (HEIs) saw e-learning as offering high potential for business development and quality improvement, and subscribed to the prediction that the teaching paradigm would somehow change. In practice, e-learning is complex and involves considerable individual and institutional change, beyond the provision of technology (Zentel et al., 2004). In 2005 , we are on the runway to the second stage but more lift and understanding is needed to progress.

Unlike the early aviators who had their focus firmly on powered lift off, in universities those purposes, missions, new markets and intentions are far from obvious and interact in a very complex way with the available learning technologies. To understand and undertake the rethinking and associated organizational changes, the natural intrinsic conservatism in universities must be surfaced, explored and addressed (Westera, 2004).

\section{The introduction of learning technologies}

In 2005, almost every HEI is planning to use one or more VLEs, for one reason or another (Dickson, 2004; Garrett \& Jokivirta, 2004), and almost every HEI in the United Kingdom is attempting to do so whether for distance or blended learning (Calvert, 2005). But, with a few exceptions, VLEs are 'flapped' learning — an attempt at a transference of existing pedagogy. In other words, most HEIs have adopted a 'substitutional' approach, while also believing that there would somehow be a natural pathway to more radical pedagogical change.

As teaching on campuses is mainly an individual and traditional craft, it is unsurprising that most academics and their supporters cannot see beyond the flapping of their wings at this stage and so continue to preserve their existing and familiar pedagogical approaches, defined along disciplinary lines, regardless of the introduction of new technology (Anderson et al., 2005). Those academics who have fully engaged with e-learning either explored learning technologies for their novelty or have been driven by a naïve belief in their economic benefits. When some evaluation and research started there was much 'talking up' by those who were caught up in the potential along with overcritical dismissal by those lagging behind, often with good reason (Sullivan \& Czigler, 2002). To date, the differences and similarities between online, traditional distance and physical-based teaching have been little understood, leading to confused notions of the panacea of 'blend'. 
As learning technologies become increasing deployed in higher education, the hardware and connectivity reduces in price. Fast, reliable networks, some highly mobile, are commonplace. Overselling and exaggerated claims from commercial providers, and perhaps overzealous responses from the open source promoters, have led academics to focus on the explicit attributes of a learning technology rather than the inherent pedagogical assumptions, their intrinsic potential and their value for the development and achievement of new ideas, missions, markets and improvements in quality. In 2005, as the hype from around the turn of the Century has died away, only VLEs (principally Blackboard and WebCT in the United Kingdom) and lecturesupport systems (especially PowerPoint) have been widely employed (Zemsky \& Massy, 2004). There is a lack of institutional learning from the many thousands of isolated experiments and innovations as, in many universities, internal investment, reward, recognition and approval systems do not encourage systematic change or experimentation (Calvert, 2005).

There continues to be many unanticipated consequences related to the previous naïve 'pushing' of learning technologies (Goodyear, 2005). Typically there is banal and obvious usage of a learning technology. For example, it is a common belief among managers, policy-makers and strategists that, by encouraging academics to post some notices or PowerPoint slides on a VLE, an e-learning process emerges that will benefit learning, and that in some magical way such academics will 'cross the divide' and understand motivating online learning systems or even remote knowledge construction. Or as a response to participants' logging on to bulletin boards erratically, strict controls are imposed on postings on asynchronous networks, resulting in diminution of their key attribute of flexibility and choice in e-learning. The result is expensive mistakes, loss of quality and much frustration.

Learning technologies are not transparent, their properties are not obvious and they do not broadcast their utility. No VLE will ever be enough in itself to create great e-learning. However, teachers and designers frequently attribute the capacity for doing or achieving the learning to the technology. It just cannot be successful without appropriate, well-supported and focused human intervention, good learning design or pedagogical input and the sensitive handling of the process over time by trained online tutors. In addition the complexity is further increased by the impact of ICT occurring at differing intervention points in the HEI-from the 'micro' level such as animations in teaching content, to the 'meso' level, such as changes to library facilities or provision of media centres, to the 'macro' policy and large-scale collaborations (Zentel et al., 2004).

\section{Modes of learning}

Outside the single-mode distance universities, there is considerable evidence that by 2005 the dominant mode to which HEIs aspire is what Zentel et al. (2004) cutely call 'Alma mater multimedialis'. By this they refer to the way campus-based universities are gradually integrating online components into their more traditional face-to-face approaches as 'add-ons' or in a blended mode. Zentel et al. suggest the popularity of 
multi-mode results from the need to address the desire of younger undergraduates to attend a campus while also increasing flexibility and value through multimedia and online provision. Distance education is similarly challenged in the twenty-first century, both as a field of practice and of study (Calvert, 2005). Even for distance education, where technology has been integrated from the beginning of its development, Moore (2003) notes that 'the organisation, philosophies and issues are not technologically specific'. From all the literature on the topic of modes, there are two dominant features. First, any approach to 'one technology and pedagogy fits all' is pretty much doomed to flap and then crash, with little transferability of the reasons associated with the failures to benefit new attempts. Second, there is challenge to the quality and utility of the research to inform both policy and practice, leading to poor results associated with the embedding of innovation in HEIs (Calvert, 2005; Latchem, 2005).

\section{Institutional change}

There are well-rehearsed intentions and plans to achieve economic and quality benefits from the introduction of e-learning - and many HEIs have been seduced by this potential, in part because of their competitive and demanding market places (Collis \& van der Wende, 2002). Part two of the e-University Compendium offers a wide range of international examples from recent years (Higher Education Academy, 2005). However, these reports illustrate that many HEIs have a somewhat shaky approach to future e-learning markets and an aspirational rather than realistic approach to the achievement of student numbers together with the lack of capacity to adapt, especially from the perspective of academic staff and institutional structures. Innovations in the democratic and conservative decision-making structures of universities have always had somewhat of a hard time. E-learning creates further pointed tensions in these political processes due to the pace of change, the investments required, and the need for involvement of more staff and stakeholders (Whitworth, 2005). Consequently, many approaches that deployed e-learning have failed or wasted large amounts of money in the recent past because universities were taken by surprise about the low conversion rate of potential markets into actual registrations, the difficulty in reaching a global market through advertising or agents, the requirements of higher levels of resources and the slow time to market, and hence were unable to change internally sufficiently fast and well.

The costs of e-learning attract much more attention and challenge than the investment in more conventional learning infrastructure. On-campus costs are often in legacy systems and buildings. E-learning costs have been the subject of studies in the United Kingdom (for example, Rumble, 2001, 2004; Ash \& Bacsich, 2002). E-learning, like distance learning, requires more up-front investment (compared with campus-based teaching) but offers a low cost and sustainable model over several years if large numbers of students continue to register. Attempting scaling up of e-learning through 'hand crafting' (possible in campus-based learning) cannot be supported over time. Therefore predictions need to be made of which courses are worth funding in this way, serious choices made and resources diverted in those directions. 
Any pedagogical innovation has start-up costs, especially if associated with the sharing and reusability of resources and processes. Costs associated with e-learning include the capital and direct costs of the technology itself but also the development of resources involving a number of professionals and considerable academic and technical staff development, to increase the chances of success. In the medium term, the costs associated with the human resources are likely to be higher, but offer more reliable payback and quality than the technology provision (Zemsky \& Massy, 2004).

While e-learning in higher education is now considered (indeed, sometimes welcomed by many staff) for its potential, real development beyond projects initiated by innovators has so far been modest. Most HEIs are still struggling to engage a significant percentage of students and staff in e-learning. All HEIs are vulnerable to a wide variety of pressures but have a high resistance to change. They are awash with rich resources in the form of intelligent keen individuals who are rarely appropriately directed to pedagogical innovation nor are self-motivated to radically transform their teaching. Third-generation flying - the helicopter - rarely lands in a central position on the campus!

E-learning, whether combined with other forms of teaching and learning or not, is multifaceted and involves shifts both in understanding and behaviours. Most academics responsible for both the curriculum and the pedagogical processes arising from e-learning have not made these shifts. It is most unlikely that a whole university can be 're-engineered' (Brown, 2002) to accommodate the major changes associated with e-learning. Many academics still view e-learning as impersonal, constraining and insufficiently adaptive to the needs of a wide variety of learners. This view has arisen mainly because of the over-simplistic approaches in the earlier days. To date, much of the focus has been into the development of technologies or top-down policy aspirations, and not on the human dimensions, scaling-up and embedding of innovation and the associated management of change (Tham \& Werner, 2005).

\section{Pedagogy}

Academic staff are naturally reluctant to change their methods of teaching and learning (and move from stage one-flapping - to stage two-flying) without a deep understanding of why and how and what the impact will be in terms of quality and any resultant benefits. Furthermore, most staff who are inexperienced in e-learning initially believe that it is about technical 'solutions' rather than pedagogical innovation. Given the research imperative in most institutions, there are few direct benefits for academics to innovate in their teaching, and as such staff development and support are essential to promote and encourage uptake. To engage large numbers of academics, any approach must seek to ensure that ownership, not only of content but also of pedagogy, continues to lie directly within academic departments, but also recognizes that a wide variety of supportive mechanisms must underpin the continued developments. 
Some writers have claimed that there has been a recent shift away from traditional views of teaching and learning towards constructivist views of knowledge sharing (for example, Dickey, 2003), because many learning technologies would seem to offer new and wider opportunities (Jones, 2004). This has almost become an accepted mantra and, although interesting in raising awareness of differing models and philosophies of learning, has largely added to the naivety surrounding deep use of learning technologies in practice. For example, the values embedded in many commonly used VLEs leave a residue that is clearly transmissive rather than constructed and hence adds to the banality and confusion, even disappointment, in the learning and teaching experiences (Sullivan \& Czigler, 2002; De Freitas \& Oliver, 2005).

Individuals and small groups, such as departments in universities, have their own desires, abilities, histories and preferred artefacts; in other words, they are closely situated. Universities themselves consist of cultural, historical, institutional and power-constructed contexts (Becher \& Trowler, 2001; Whitworth, 2005). At present, few higher education teachers choose to imagine a world in which classrooms are abandoned, since so much of their appreciation of learning has grown up in them. In single-mode distance institutions like the UK Open University, there are strong traditions based on openness, procedures and the student experience. Such institutions have their own challenges of embedding pedagogical and technological innovation, of a somewhat different nature. Throw a learning technology into these heady mixes, introduce a little naively, and it is sidelined, without a thought, or worse becomes the focus of anger and bitterness.

More positively, and probably as a counter response to the over-emphasis on technologies that has occurred to date, the term pedagogy has once more surfaced. The early focus on technological infrastructure has given way a little to increased awareness and dialogue on pedagogy, connectedness and in blending newer and older approaches to learning. The design of learning activities and the links between online and common tasks in teaching have become much more important (Salmon, 2002; McAlpine et al., 2004). More higher education teachers talk of learning outcomes and assessable processes. The plane taxis to the runway.

\section{The contribution of research}

With the current focus on the research assessment exercise, a number of writers recently explored the key issue of research into ICT as a disciplined field of inquiry as opposed to one of opinion and belief, however eloquent or with surface plausibility (see for example, Gardner \& Galanouli, 2004). This can be welcomed as a first step towards the second stage of powered flying for e-learning. Research has the potential to inform decision-making and policy-making at the macro national levels, but dialogue between policy-makers, researchers and practitioners is only now starting to have an impact. Within institutions, at the meso and the micro levels, research needs to raise its credibility as well as its dissemination.

Research into open and distance learning over more than 30 years has identified what works, what does not, what constitutes excellence and what adds real value to 
student experiences. Much is relevant to e-learning and blended modes. In particular, there is growing recognition of the need for evidence-based research especially associated with achieving positive and successful change processes and in associated staff development (see, for example, the Department for Education and Skills elearning strategy of 2005) (DfES, 2005). However, such knowledge is of no value if it cannot be used in a flexible and contextualized manner, and in particular be embedded into the everyday teaching processes of a university.

Most academics are motivated, directed even, to undertake research into the burning questions of their own discipline, even if teaching is something they also enjoy. Those that attempt research into their teaching find that generalizing and modelbuilding is all but impossible from highly individual studies with multiple variables. It is realistic to recognize that implementing e-learning is a hugely complex undertaking with multiple contexts and stakeholders-and risks (Pittard, 2004). One area where this critique is especially true is in the drive towards the implementation of effective strategy at an institutional level (Lisewski, 2004). The taste for looking beyond the next year in terms of e-learning, and hence being able to develop staff and resources for medium-term futures, has been tainted by just such a lack of evidence, and, even worse, some expensive crashes. Some of the failures have a high profilesuch as the UK e-University demise-but most happen quietly and painfully within individual institutions (Latchem, 2005). Some writers argue that integrating and scaling-up of ICTs into everyday teaching and learning processes may even be inherently paradoxical, because of the nature of the internet as individualistic and exploratorydisruptive even (Somekh, 2004).

I undertook a content analysis of the Online Educa Conference Proceedings for 2003 (www.online-educa.com/en/) as a 'snapshot' of the research focus (Salmon, 2004a). There was considerable evidence that e-learning had become much more concerned in the twenty-first century with macro analysis, value for money, incorporation and integration of multimedia, as well as blended learning and adherence to standards and benchmarking. Although there was strong interest in networking and collaboration between institutions and many exchanges of experiences, there was little evidence of emergence of harvesting, transferring and testing the sturdiest models and principles. Essentially, while e-learning is no longer a novelty, it is now facing the same problems that conventional HEIs have faced for many years-quality assurance, assessment and the exchange of best practice. Because of its innovatory approach, missionary zeal and army of challengers and sceptics, e-learning healthily faced these issues head on, early on in its history.

Broad areas now to be addressed should include the development of concepts, theories, principles, rigorous and appropriate methodologies, identification, promotion and support of excellent sustainable, transferable practice and models of change related to human intervention and sustainability. In addition, focusing on e-learning is a key way of providing for multidisciplinary and interdisciplinary research agendas through virtual research environments. My own interest is to try and establish some basic models of practice to provide frameworks for further contextualized work. 


\section{Introducing e-learning successfully}

My argument in this paper is that, despite the fact that e-learning (and its role as a change agent) figures highly, and sometimes even wistfully, in the aspirations of many policy-makers and senior managers, there is considerable evidence that most HEIs are still struggling to engage a significant percentage of students and staff in e-learning, and real development beyond projects by innovators has so far been modest. Research is currently not providing answers to this problem and more models are needed to demonstrate the transferability and scalability of e-learning.

The technology is now just about robust enough for attention to turn to business development and pedagogical innovation and away from technical 'solutions' and 'fixes'. There are two main ways in which e-learning can be introduced into traditional teaching, whether on campus or at a distance. One is through large-scale centralization and provision of professional services. The second is more incremental, perhaps a little slower and more challenging, but gradually involving all members of staff to make their contribution. This involves the choice of easy-to-use technologies and investment in personal and departmental learning and development. The latter has the advantages of developing capacities for the longer term and keeping 'ownership' with the academics and their departments.

\section{Strategic underpinnings to an e-learning strategy}

We can distinguish between a moderate change strategy and a more radical approach (Johnston et al., 2001). An incremental approach involves cautiously enhancing existing practice through introducing well-rehearsed and easy-to-use learning technologies. At the same time, a research agenda that brings forward weaker signals from the learning technology's environment, and indeed society's, suggests a more challenging approach to changes in the use of learning technologies and the associated pedagogy. This more radical approach ultimately impacts on organizational structures - a more risky but transformational approach. We need to find a way that the two approaches are not mutually exclusive, and can be turned into practical actions within an HEI.

One dimension of a strategic framework is to distinguish between core technologies and peripheral learning technologies (Salaman \& Asch, 2003). The core forms the basis of current activities that must be maintained and, since effort and investment have been put into them, they do not present a high risk. We could consider the use of commercial VLEs and the e-resources provided by a university library to be core technologies in 2005. As previously explained, nearly all universities are currently adapting to using VLEs, so in the medium term these core capabilities will no longer be innovative. Peripheral technology is on the 'edge' and offers more choice. A range of potential new learning technologies need therefore to be included in the strategy. These can be different from the VLE or incorporated into or extending it. Some peripheral technologies do become mainstream over time so the strategy needs ways of including potential new technologies and preparing for new capabilities. Hence, it is also 
important to focus on building increased capacity and capability for e-learning innovation and on continually looking ahead to potential and new learning technologies and their applications related to a mission or objective. One word of caution regarding how these concepts apply to the introduction of educational technologies in HEIs: the core capabilities that are obvious or are most enjoyed or admired within a university may not be strategically relevant. Instead they need to be those that a wide range of 'stakeholders' (students, clients, partners, funding bodies) both perceive and value.

The pace of technological change shortens the lifespan of most technology-based resources, but, as discussed, all universities demonstrate exceptional slowness to transform. When a particular technology or platform is adopted (e.g. Blackboard) it is very difficult to change later. Key capabilities, however, have the potential to be more durable than the technological resources on which they are based.

Innovative capacity promotes the transfer of knowledge (see Bell \& Bell (2005) for a brief review of relevant models of innovation). For example, some universities are good not only at developing, but also exploiting and transferring their research. Collaborations and alliances with others or consortia and joint projects offer ways to explore innovation and peripheral technologies at somewhat lower risk. Each technological development must be placed in its context and culture. Humans, and most certainly academics and teachers, cannot be reduced to mere tool users (Hickman, 1990). Each individual institution has a need to develop e-learning to match its own culture but within an overall context of common development needs with other HEIs (Garcia, 2004).

My proposal is that a suitable framework for an e-learning strategy in universities could be based on a 'resource-based' definition (Salaman \& Asch, 2003) of the match that a university can make between its internal resources and skills, and the opportunities and risks created by its external environment. Such a framework both implies identifying an individual institution's core capabilities and existing strengths (what it is good at, what makes it special), and how a strategy can take advantage of these in a competitive world (what it can do well and differently). A strategy based on those kinds of strengths would be more durable, and harder to imitate than 'off-the-shelf' strategies (Hamel \& Valikangas, 2003) or those based on traditional market-led approaches (Salaman \& Asch, 2003). Thus, choices of where to be innovative and where to increase the development of e-learning should not be based on a bland view of 'market' but on a more complex view of the value of e-learning meeting the university's mission and objectives as well as playing to its distinguishing institutional strengths (Richards et al., 2004).

In 2005, the Higher Education Funding Council for England also recognized that HEIs are most effective if allowed to develop their own directions within a supportive framework. What we need at this stage is to create practical frameworks to provide usable models to test and develop in different contexts and over time. Two key government policies set out an agenda for the immediate future, especially in terms of the difficulty of truly 'embedding' e-learning into everyday practice including uncertain leadership, lack of true innovation and lack of professional expertise (Laurillard, 2004; see Appendix 1). 


\section{Proposed framework for e-learning strategies-the example of Leicester}

I will now describe the University of Leicester's attempt to address these issues. Leicester is typical of the traditional campus-based university keen to capitalize on the benefits of e-learning, while also having to move from twentieth-century distance learning to twenty-first-century online learning for its large-scale distance programmes.

Late in 2004, I was charged with preparing a strategic framework for the development of e-learning at the University of Leicester (www.le.ac.uk). Fortunately the university had recognized, prior to my appointment, that e-learning needed to be developed with appropriate pedagogical and customer-driven underpinnings. A Director of Distance Learning Administration was appointed at the same time as I was, with an agenda of administrative and systems developments. His strategy and actions were developed separately from the e-learning strategy, although each clearly underpins the other.

In a 'research-led old' university, dominated by campus learning in traditional subjects, the process of strategy development needed to be one of deep engagement of groups of management and staff, academics and support departments. As a start, there was history of postgraduate distance learning, mainly in overseas markets and embedded in fairly autonomous separate units in various departments. 'Tribal' and 'Blackboard' were the two VLEs already in use in some pockets on campus and for distance study. There were well-established staff development and support process for use of learning technologies.

The issue was far from a question of 'which VLE?'. I recognized that I was facing a diverse and complex field concerning a mix of pedagogical changes throughout the institution and alterations in the way academics and support staff conducted their business on a day-to-day basis (Westera, 2004). I needed to develop insight into a range of fundamentals such as resources, control and autonomy and the power of commitment to disciplines and departments. There was allegiance and support from senior management and from a wide variety of staff. There was a need for the strategy to harness enthusiasms and focus resources as well as practical knowledge, while avoiding directive approaches.

In researching and developing both a process and a framework for the strategy, I was strongly influenced in my thinking by my previous work on models of e-learning and staff development (for example, Salmon, 2004b), as well as 16 years as a change management academic at the UK Open University.

My approach to engaging others in the university with the e-learning strategy addressed a number of key issues, outlined earlier in this paper. I wished to ensure that the model proposed took account of the following:

1. The role for research into innovative pedagogy, linked directly to learning technologies.

2. The development of both core and peripheral learning technologies.

3. Realistic approaches to marketing and market development both for distance and blended learning, especially in terms of student numbers and support. 
4. An embeddedness in the university's overall aspirations, identified mainly through its existing formal plans and strategies but interpreted through formal and informal discussions.

5. The need to determine and make explicit the purpose of pedagogical innovation and the objectives of the scaling-up of e-learning.

6. The importance of surfacing existing values in the university in a way that the best resources, projects and motivations were preserved.

7. The strategy needed to sit within wider national frameworks and directions.

Innovation and change development in universities can never be a mere rational process (Jones \& O'Shea, 2004). Developing e-learning still involves considerable risk and opportunity costs, and few institutions have the resources to bet or a thirst for chancy ventures, and Leicester was no exception while keen on pedagogical and quality development. The model developed as the basis of the strategy needed to be easy to understand and relate to at a variety of levels, while still offering opportunities to those with a taste for innovation. Given the huge pressure on all staff towards entrepreneurial, teaching and research activity, the strategy needed to have an element of 'enticement' and comfort about it.

While I was interested in the models of innovation such as Rogers (1993) and Somekh (1998), the linear process views appeared too simple to be useful as a framework for considering the complexity involved in e-learning in HEIs. Hence a matrix approach emerged. Readers may recognize the roots of the framework in the Ansoff Matrix (Ansoff, 1965) which was developed, adapted and tested for use here in the specific e-learning strategy and HE context.

\section{The e-learning and pedagogical innovation strategic framework}

\section{Summary}

- Quadrants one, two and three in Figure 1 represent the deployment of a university's existing core capabilities and capacity through incremental innovation.

- Quadrants one and two suggest deployment of a university's key strengths in teaching excellence but with adjustments to new technologies.

- Quadrant three suggests deploying the understanding of technologies already in place to promote business development, solve problems and increase quality of all kinds.

- Quadrant four represents a more radical view of change using peripheral technologies, new products and new markets and missions.

\section{Quadrant One}

The upper left-hand box of the matrix suggests achieving growth with established core technological products and processes such as VLEs and e-libraries, embedding them 


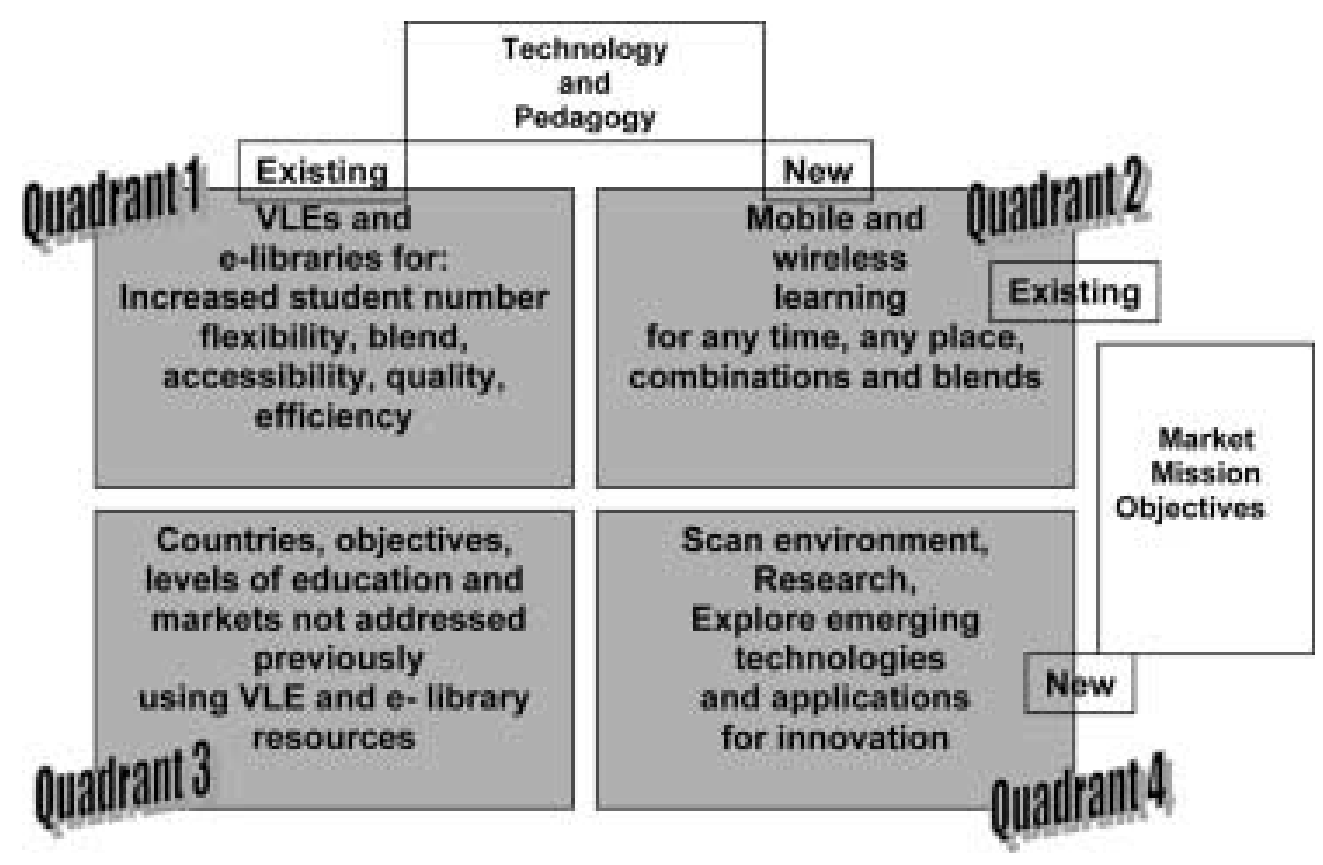

Figure 1. The e-learning and pedagogical innovation strategic framework

further into teaching and learning processes and using them for increasing numbers of purposes and students. Here is the gradual evolution from campus and/or traditional paper-based distance learning to pedagogically sound e-learning.

Much can be achieved by deploying 'off the shelf' technologies such as commercial VLEs but they require careful business planning, investment in staff development and support, and excellent provision of ICT within university systems. They also require astute planning of markets, mission, objectives, student requirements and the resources for the support and development of the technology.

The university should first identify and target those areas where there is potential for growth, rapid improvement in quality or efficiency gains. The aim can be to move more of its regular learning into the e-environment but in a way such that will enable it to pilot transferable or scalable processes. To start with, the focus can be to further develop communication and group teaching in the online environment, rather than from print to online resources. At a discipline level, subject centres (www.heacademy.ac.uk/474.htm) can provide free academic courseware or learning objects that can be shared, versioned or reused (Mason et al., 2005). Content is usually not viewed as a major differentiator by potential students: value lies in brand, support, group teaching, peers and communication.

Personalization and choice based on learning needs is the first step away from the limitations inherent in printed texts, and face-to-face classrooms, and applies well as a mission for quadrant one. As access to a wide range of resources becomes easier, and as the number of resources multiplies, it will become more possible to tailor 
access to the needs and interests of the individual learner while avoiding loss of economies of scale.

In this quadrant the university will be able to 'keep up' with the increasing uptake of e-learning and offer acceptable online learning to students. The university will then be in a good position to expand into new locations, respond to funding opportunities and into new types of courses.

\section{Quadrant Two}

The upper right-hand quadrant (existing mission/new technologies) addresses the many new learning and mobile technologies now available. However, most of the newer widely used technologies such as Smart phones, I-Pods, and GPS applications have not been developed for learning and need good understanding of potential teaching applications to be successful in new contexts. These technologies are currently considered peripheral. Some, however, may become core in the near future.

The implications of wireless networking are that, because content and communication is available anywhere, learning is no longer tied to a particular location. As more standardized encoded and syndicated content delivery becomes readily available, there will be little, if any, limitation on the place or manner in which learning may be available.

Many new technologies are appropriate for off-campus use, as combinations and blends, for dynamic delivery of content and for human intervention and support of distance learning. There are new understandings of the use of knowledge creation, sharing and repositories that can be deployed. Many technologies can be channelled through the VLE but are not limited by the obvious VLE operations.

Pedagogies in this quadrant need more exploration than those in quadrant one but it is still possible to imagine a migration between flapping and flying. Clearly smallscale pilots need to be undertaken that focus on the changing nature of pedagogy, rather than rampantly developing more and more technological features. In this quadrant, the university can be confident in offering small-scale pilots with existing students and clients, with a view to developing appropriate e-learning pedagogy through evaluation, feedback and research. Staff development and new systems and processes will be necessary for scaling-up of offerings.

\section{Quadrant Three}

The lower left-hand box (existing pedagogies and technologies/new missions and markets) represents using learning technologies to address different and new markets, missions, levels and disciplines of learning and teaching (compared with quadrant one) but using the core expertise and technologies already developed. Realistic approaches must be taken to the market to reduce risks as far as possible. As e-learning depends on volume, there should be a minimum contracted commitment before new e-learning processes are developed. In this quadrant, marketing can take place to 
new countries or through new distribution channels with some confidence in the elearning process.

Learning objects - a piece of digital resource, broken into small reusable chunks, that can promote learning - clearly fit into this quadrant, as they can be used in a wide variety of circumstances. Similarly the use of personal repositories, wikis and blogs can be a system for managing and sharing both pedagogical and content knowledge across a wide range of new missions.

There is an opportunity in quadrant three to use web-based technologies such as VLEs to enable 'joining up' of e-resources across the university community to enable students to make stronger and easier connections between the subject areas they study and the services they can use. An aspiration for this quadrant could be to ensure that every student of a university, regardless of location or mode of learning, receives equivalent services and learning experiences.

\section{Quadrant Four}

The lower right-hand box (new/new) is the most challenging, risky and potentially rewarding. Research projects about e-learning are being published that go beyond the simplistic 'what works' scenarios of stage one of technology introduction. They need exploring and bringing together into usable principles and understandings along with appreciation of their transferability into teaching and innovation in a university. This quadrant offers the greatest potential to successfully put a university on the e-learning map.

Clearly the technologies here will be peripheral but the research will position the university well for developing local expertise, capabilities and competencies should they become core in the future through diversification. The university should allow new strategies to emerge to support an assessment of effective directions and the associated risks.

Engagement with this quadrant will require each university to continually scan both the technology and marketing environment and develop one or two innovative projects or seek several smaller ones using peripheral technologies.

\section{Discussion}

You have seen some of the films of humans' early attempts to fly-early adopters of e-learning had a similar tendency to flap their wings. They fell into two main categories. Some assumed that the cyber environment is much the same as earth-bound learning and simply required better motivation for those along for the ride. Tell that to the first victims of powered flight! Others observed the key aspects of learning in the classroom and burnt out their human pilots by insisting they work harder and longer to make mediocre design succeed.

If we avoid sliding assumptions about pedagogy around from one technological environment to the other then we quickly find out that teaching online has almost nothing to do with computers and everything to do with time, motivation, knowledge 
and the new agency of cyber-experience, as well as good, appropriate teaching. We need to understand the appropriateness of the application and the deep-rooted change processes that lay alongside them so they will succeed in their objectives.

Broad areas now to be addressed should include the development of concepts, theories and rigorous and appropriate methodologies, identification, promotion and support of good practice and models of change related to human intervention and sustainability. In addition, focusing on e-learning is a key way of providing for multidisciplinary and interdisciplinary research agendas in the applications of core and peripheral learning technologies and the associated innovative pedagogy.

It is true that, in a virtual environment, academics are denied the ability to 'wing it' that comes with the territory of face-to-face classes and instead need to articulate and plan exactly what it is that they do to create those magic moments that otherwise appear to occur 'naturally'. However, once their strategy, tactics and craft are surfaced and polished, they gain, or regain, a new level of e-self-assurance. Flapping is reduced and confidence returns.

\section{Conclusions}

The e-learning and pedagogical innovation framework at Leicester provided an appropriate platform for the hundreds of formal and informal discussions needed to develop an e-learning strategy for the university. The strategy was adopted by the University Senate, with a detailed costed implementation plan in July 2005. As I write, implementation has commenced and evaluation processes are in place. I offer the framework here for feedback, critique and exploration by others. I hope that it will provide an example of an attempt to capture the complexity of developing and implementing an e-learning strategy and that it will contribute to the understanding of change processes in HEIs associated with the introduction of ICT in learning and teaching. It is also intended as a pointer away from the technology-driven focus on elearning to date, which has clearly resulted in flapping not flying. New approaches are so much needed if e-learning is to succeed in becoming successfully embedded in HEIs to the benefit of learners and teachers alike, and within a climate of promoting e-learning and teaching research.

\section{References}

Ash, C. \& Bacsich, P. (2002) The costs of networked learning, in: C. Steeples \& S. Jones (Eds.) Networked learning: perspectives and issues (London, Springer-Verlag).

Anderson, T., Annand, D. \& Wark, N. (2005) The search for learning community in learner paced distance education: or, 'having your cake and eating it, too!', Australasian fournal of Educational Technology, 21(2), 222-241.

Ansoff, H. I. (1965) Corporate strategy (New York, McGraw-Hill).

Becher, T. \& Trowler, P. (2001) Academic tribes and territories: intellectual enquiry and the cultures of disciplines (Buckingham, Open University Press).

Bell, M. \& Bell, W. (2005) It's installed ... now get on with it! Looking beyond the software to the cultural change, British fournal of Educational Technology, 36(4), 643-656.

Brown, S. (2002) Re-engineering the university, Open Learning, 17, 231-244. 
Calvert, J. (2005) Distance education at the crossroad, Distance Education, 26(2), 227-238.

Collis, B. \& van der Wende, M. (2002) Models of technology and change in higher education, report, University of Twente. Available online at: http://www.utwente.nl/cheps/documenten/ictrapport.pdf (accessed 7 September 2005).

De Freitas, S. \& Oliver, M. (2005) Does e-learning policy drive change in higher education? A case study relating models of organizational change to e-learning implementation, fournal of Higher Education Policy and Management, 27, 81.

Department for Education \& Skills (2005) Harnessing technology: transforming learning and children's services. Available online at: http://www.dfes.gov.uk/publications/e-strategy/ (accessed 14 November 2005).

Dickey, M. D. (2003) Teaching in 3D: pedagogical affordances and constraints of 3D virtual worlds for synchronous distance learning, Distance Education, 24(1), 105-121.

Dickson, T. (2004, February) Things to come, conference opening address at When worlds collide, FISC infoNet Conference, York (York, JISC infoNet and HEFCE).

Garcia, B. C. (2004) E-learning in a knowledge capital: the Manchester universities experience, Proceedings of the Online Educa Conference, Berlin (Berlin, ICWE) 426-431.

Gardner, J. \& Galanouli, D. (2004) Research into information and communications technology in education: disciplined inquiries for telling stories better, Technology, Pedagogy and Education, 13(2) $147-161$.

Garrett, R. \& Jokivirta, L. (2004, October) Online learning in commonwealth universities: selected data from the 2004 Observatory Survey, Part. 1, Report no. 20 (London, The Observatory on Borderless Higher Education).

Goodyear, P. (2005) Educational design and networked learning: patterns, pattern languages and design practice, Australasian fournal of Educational Technology, 21(1), 82-101.

Hamel, G. \& Valikangas, L. (2003) The quest for resilience, Harvard Business Review, September, 81(9), 52-63.

Hickman, L. (1990) fohn Dewey's pragmatic technology (Indiana, Indiana University Press, Bloomington).

Johnston, R., Fitzgerald, L., Markous, E. \& Brignall, S. (2001) Target setting for evolutionary and revolutionary process change, International fournal of Operations and Production Management, 21(11), 1387-1403.

Jones, C. (2004) Networks and learning: communities, practices and the metaphor of networks, ALT-F, 12(1), 81-93.

Jones, N. \& O'Shea, J. (2004) Challenging hierarchies: the impact of e-learning, Higher Education, 48, 379-395.

Latchem, C. (2005) Failure-the key to understanding success, British fournal of Educational Technology, 36(4), 665-667.

Laurillard, D. (2004) The next level in e-learning, Proceedings of Online Educa Berlin, (Berlin, ICWE) 452-455.

Lisewski, B. (2004) Implementing a learning technology strategy: top-down strategy meets bottom-up culture, ALT-f, 12, 175-187.

Mason, R., Oblinger D. \& Mackintosh W. (2005) An ODL perspective on learning objects, Open Learning, 20(1), 5-13.

McAlpine, I., Koppi, T., McLean, J. \& Pearson, E. (2004) Course developers as students: a designer perspective of the experience of learning online, ALT-F, 12(2), 147-162.

Moore, G. (2003) Preface, in: M. G. Moore \& W. G. Anderson (Eds.) Handbook of distance education (Mahwah, NJ, Lawrence Erlbaum Associates), ix-xii.

Pittard, V. (2004) Evidence for e-learning policy, Technology, Pedagogy and Education, 13(2), $181-193$.

Richards, R., O'Shea, J. \& Connolly, M. (2004) Managing the concept of strategic change within a higher education institution: the role of strategic and scenario planning techniques, Strategic Change, 13, 345-359. 
Rogers, E. M. (1993) Diffusions of innovations (5th edn) (New York, The Free Press).

Rumble, G. (2001) Just how relevant is e-education to global education needs?, Open Learning, 16(3), 223-232.

Rumble, G. (2004) Papers and debates on the economics and costs of distance and online learning. Bibliotheks und Informationssystem der Carl Ossietzky Universitaet, Oldenburg.

Salaman, G. \& Asch, D. (2003) Strategy and capability: sustaining organizational change (Oxford, Blackwell Publishing).

Salmon, G. (2002) E-tivities: the key to active online learning (London, Taylor \& Francis).

Salmon, G. (2004a, December) How things have changed, Online Educa Conference Proceeding, Berlin, (Berlin, ICWE) 388.

Salmon, G. (2004b) E-moderating: the key to teaching and learning online (2nd edn) (London, Routledge).

Somekh, B. (1998) Supporting information and communication technology innovation, in higher education, Fournal of Information Technology for Teacher Education, 7(1), 11-32.

Somekh, B. (2004) Taking sociological imagination to school: an analysis of the (lack of) impact of information and communication technologies on education systems, Technology, Pedagogy and Education, 13(2), 163-179.

Sullivan, K. \& Czigler, P. (2002) Maximising the educational affordances of a technology supported learning environment for introductory undergraduate phonetics, British fournal of Educational Technology, 33(3), 333-343.

Tham, C. M. \& Werner, J. M. (2005) Designing and evaluating e-learning in higher education: a review and recommendations, fournal of Leadership and Organizational Studies, 11, 15.

Higher Education Academy (2005) e-University compendium, Part Two. Available online at: http:// www.heacademy.ac.uk/2249.htm (accessed 7 September 2005).

Westera, W. (2004) On strategies of educational innovation: between substitution and transformation, Higher Education, 47, 501-517.

Whitworth, A. (2005) The politics of virtual learning environments: environment change, conflict and e-learning, British fournal of Educational Technology, 36(4), 685-691.

Zemsky, R. \& Massy, W. F. (2004) Thwarted innovation: what happened to e-learning and why. Final report for the weatherstation project of the Learning Alliance, University of Pennsylvania.

Zentel, P., Bett, K., Meiter, D. M., Rinn, U. \& Wedekind, J. (2004) A changing process at German universities-innovation through information and communication technologies?, Electronic fournal on e-Learning, 2(1), 237-246. 


\section{Appendix 1}

\section{From the DFES e-learning Strategy $15^{\text {th }}$ March 2005: Transforming learning and children's services.}

Technology has been used in education for many years. It has not yet transformed teaching and learning, but it has made a major impact in many schools, colleges and universities. It has also made information more accessible and administration more efficient. We can achieve more in Higher Education by:

- Ensuring that research in e-learning and the pedagogy of subject teaching is given full recognition

- Incorporating the use of online learning into new staff courses and other staff development

- Development programmes to encourage the wider use of ICT to promote individual learning

www.dfes.gov.uk/publications/e-strategy/

\section{HEFCE E-learning Strategy $9^{\text {th }}$ March 2005: HEFCE strategy for e-learning}

"Although there has been rapid development [of ICT] in HE, our evidence base and responses to our consultation suggest that institutions are still struggling to 'normalize' e-learning as part of higher education processes. It is timely to ... support the sector further in taking best advantage of these developments."

"That does not mean telling universities and colleges what their aims for e-learning should be, nor how they should go about reaching them. But it is about describing overall aspirations for how e-learning can transform learning and teaching, and about supporting institutions in setting their own visions and plans." 